\title{
Correction to: Oral esketamine for treatment-resistant depression: rationale and design of a randomized controlled trial
}

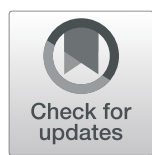

Sanne Y. Smith-Apeldoorn ${ }^{1 *}$, Jolien K. E. Veraart ${ }^{1,2}$, Jeanine Kamphuis ${ }^{1}$, Antoinette D. I. van Asselt ${ }^{3}$, Daan J. Touw ${ }^{4}$, Marije aan het Rot $^{5}$ and Robert A. Schoevers ${ }^{1}$

\section{Correction to: BMC Psychiatry (2019) 19:375 https://doi.org/10.1186/s12888-019-2359-1}

After publication of our article [1] we were notified that Fig. 1 was wrongly presented.

The correct figure and corresponding title is presented below:

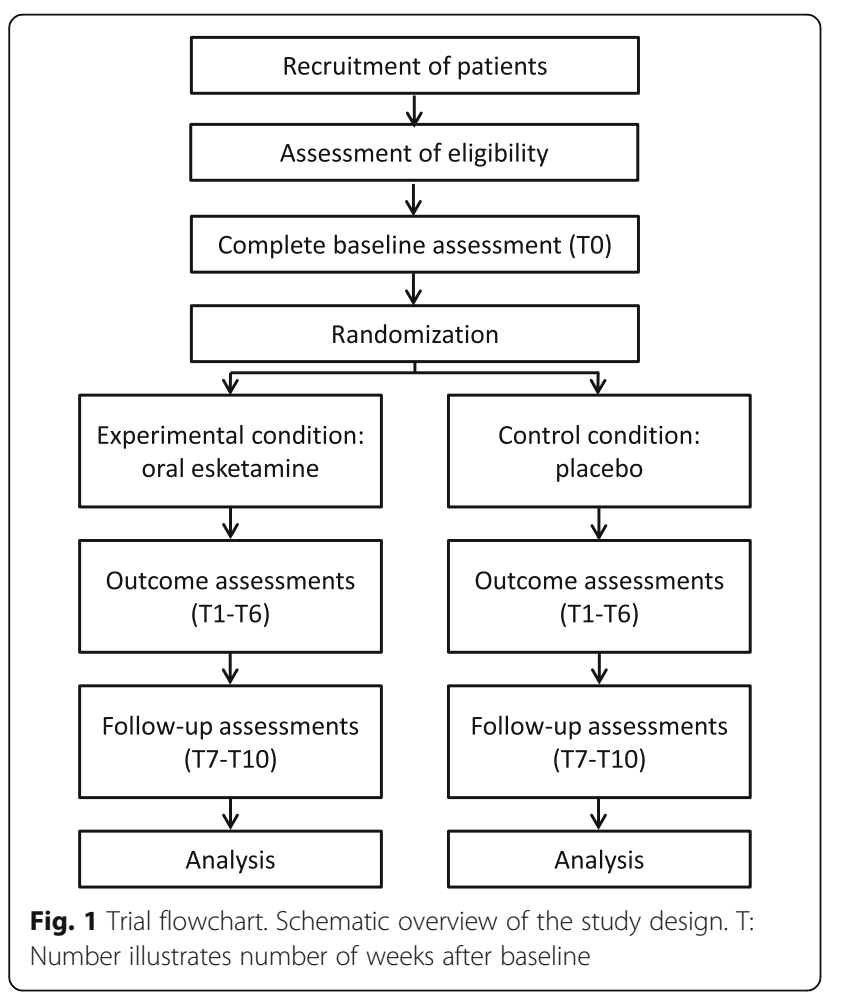

The original article can be found online at https://doi.org/10.1186/s12888019-2359-1

*Correspondence: s.y.apeldoorn@umcg.nl

'Department of Psychiatry, University of Groningen, University Medical Center Groningen, PO box 30.0001, 9700, RB, Groningen, The Netherlands Full list of author information is available at the end of the article
The original article has been corrected.

\section{Author details}

'Department of Psychiatry, University of Groningen, University Medical Center Groningen, PO box 30.0001, 9700, RB, Groningen, The Netherlands. ${ }^{2}$ Department of Psychiatry, PsyQ Haaglanden, Parnassia Psychiatric Institute, The Hague, The Netherlands. ${ }^{3}$ Department of Epidemiology, University of Groningen, University Medical Center Groningen, Groningen, The Netherlands. ${ }^{4}$ Department of Clinical Pharmacy and Pharmacology, University of Groningen, University Medical Center Groningen, Groningen, The Netherlands. ${ }^{5}$ Department of Psychology, University of Groningen, Groningen, The Netherlands.

Published online: 08 January 2020

\section{Reference}

1. Smith-Apeldoorn SY, et al. Oral esketamine for treatment-resistant depression: rationale and design of a randomized controlled trial. BMC Psychiatry. 2019;19:375. https://doi.org/10.1186/s12888-019-2359-1.

(c) The Author(s). 2020 Open Access This article is distributed under the terms of the Creative Commons Attribution 4.0 International License (http://creativecommons.org/licenses/by/4.0/), which permits unrestricted use, distribution, and reproduction in any medium, provided you give appropriate credit to the original author(s) and the source, provide a link to the Creative Commons license, and indicate if changes were made. The Creative Commons Public Domain Dedication waiver (http://creativecommons.org/publicdomain/zero/1.0/) applies to the data made available in this article, unless otherwise stated. 